\title{
Effect of chemical and physical treatments on seed germination of Erica australis
}

\author{
Daniel Trigueros Vera ${ }^{1}$, Raquel Parra Martín² \& Sabina Rossini Oliva² \\ 1) Department of Environmental Geochemistry, Estación Experimental del Zaidín (CSIC), Prof. \\ Albareda 1, Apartado de Correos, ES-18008 Granada, Spain (e-mail: daniel.trigueros@eez.csic.es) \\ 2) Department of Plant Biology and Ecology, University of Seville, Avda. Reina Mercedes s/n, \\ Apartado de Correos 1095, ES-41012 Seville, Spain
}

Received 4 Feb. 2009, revised version received 13 July 2009, accepted 14 July 2009

Trigueros Vera, D., Parra Martín, R. \& Rossini Oliva, S. 2010: Effect of chemical and physical treatments on seed germination of Erica australis. - Ann. Bot. Fennici 47: 353-360.

We studied the germination of Erica australis seeds and their responses to different treatments (high temperature, acidic condition, cold stratification, gibberellic acid applications). Germination was very low in untreated seeds (3\%) and required approximately one month to start, but increased in all the treatments tested, reaching a value of $100 \%$ when seeds were treated with gibberellic acid ( $25 \mathrm{ppm})$. Exposure to heat and to low $\mathrm{pH}$ promotes germination and reduces time to germinate, which indicates that germination is related to passage of fire and to soil $\mathrm{pH}$. Germination of this species is also correlated with wet and cold conditions and dormancy can be classified as being of the physiological type.

Key words: chilling treatment, Ericaceae, gibberellic acid, heat treatment, low $\mathrm{pH}$, seed germination

\section{Introduction}

Erica australis (southern heath) (Ericaceae) is a dominant species in the shrublands of the western siliceous part of the Iberian Peninsula (Rivas-Martinez 1979). It is a shrub, up to $2.5 \mathrm{~m}$ high, with numerous branches and ericoid leaves. Flowering takes place in winter and early spring, and fruit ripening is completed in JuneJuly. It has numerous hermaphroditic small-sized flowers aggregated in panicles, which produce capsules with $15-45$ seeds. These seeds are very small (ca. $0.74-0.81 \times 0.20-0.28 \mathrm{~mm}$ ), with an equally small undifferentiated embryo which causes morphological-type dormancy (Baskin
\& Baskin 1998). The seeds are not dispersed very far (Valbuena \& Vera 2002) and they form seed banks where they are subjected to a wide range of temperature and humidity conditions throughout the year. Low temperatures may have a different effect on dormancy, depending on humidity conditions (Rossini Oliva et al. 2009).

Dormancy can restrict germination and seedling emergence until environmental conditions become suitable (Baskin \& Baskin 1998). Seed dormancy is defined as a characteristic of the seed rather than of its environment (Vleeshouwers et al. 1995); overcoming primary dormancy is different from stimulating germination (Thompson et al. 2003). Seed dormancy clas- 
sification, by means of the Baskin and Baskin (2004) system, distinguishes between physical, morphological and/or physiological mechanisms as controls of dormancy and can help to identify factors involved in overcoming dormancy.

It is well known that temperature, light conditions, nitrates or hormonal treatment may affect germination. In fire-prone ecosystems, conditions for seedling establishment are particularly favourable immediately after passage of fire, due to, among other factors, improved resource availability (Luna et al. 2007). This is the case for Mediterranean-type environments where many plants produce seeds that are released from dormancy only after exposure to fire-related factors, such as heat (Bond \& van Wilgen 1996, Valbuena \& Vera 2002). Different authors studied the active element in smoke responsible for germination increase (Sutcliffe \& Whitehead 1995, Brown \& van Staden 1997) and its physiological effects, in a way similar to that of gibberellic acid (Merrit et al. 2006). Thus, heat and smoke are the main components known to stimulate germination, acting either jointly or separately (Kenny 2000). However, establishment of new individuals in unburned stands is rare and little is known of the conditions involved (Cruz et al. 2003).

This study was conducted with Erica australis from the Andévalo area (Huelva province, SW of Spain) close to the Riotinto river source, which presents extremely acidic soils and intense anthropogenic perturbations over hundreds and even thousands of years, mainly involving mining activities and occasional accidental fires.

In the genus Erica, some species possess seeds that exhibit enhanced germination after exposure to moderate temperatures (Cruz et al. 2003) and others whose germination control is null, as with in the heat and mild smoke treatments (Díaz Vizcaíno et al. 2006, Rossini Oliva et al. 2009). Previous studies have suggested that in Erica, wet cold stratification is capable of overcoming dormancy and that gibberellic acid treatments enhance germination rates (Aparicio 1999, Rossini Oliva et al. 2009).

Erica australis is a facultative resprouter, which colonizes many abandoned areas, forming dense shrublands of an early- to mid-suc- cessional status (Cruz et al. 2003) and, in the mining area of Ríotinto (SW Spain), is often associated with Erica andevalensis.

This paper investigates the influence of chemical (low $\mathrm{pH}$ and gibberellic acid application) and physical (chilling and heat) treatments on germination rates and dormancy break of $E$. australis seeds, in an attempt to elucidate effective methods for seed germination in restoration programs and to study the type of dormancy present in this species.

\section{Material and methods}

\section{Plant material and study area}

Capsules of E. australis were collected in June 2007, from one homogeneous population along the banks of the river Tinto (Huelva province, SW Spain, UTM 29S 4177713/715829, $407 \mathrm{~m}$ a.s.1.), where the vegetation is dominated by Nerium oleander, Erica australis, E. andevalensis, Cistus ladanifer, $C$. populifolius, $C$. monspeliensis, $C$. salvifolius and Ulex eryocladus.

The climate of the study area is of a Mediterranean type, with mild and warm winters and extremely hot dry summers. In 2007, a mean annual temperature was $16.8{ }^{\circ} \mathrm{C}$, with a maximum temperature of $41.6^{\circ} \mathrm{C}$ and a mean annual rainfall of $553.4 \mathrm{~mm}$ concentrated in autumn and spring.

The fruits were taken to the laboratory where ripe seeds were separated and stored in paper bags in darkness at room temperature and protected from humidity until used. Just before the tests began, all the seeds had been placed in water for several minutes and those which sank were considered viable (Rossini Oliva et al. 2009). We sterilised viable seeds by soaking them in a $5 \%$ sodium hypochlorite solution for five minutes and subsequently rinsing them thoroughly with distilled water.

\section{Germination test}

Viable and sterilized seeds were placed in Petri dishes with four filter paper discs moistened with 
distilled water until saturated (agar medium in the case of gibberellic acid treatments), grown in laboratory conditions $\left(20-25^{\circ} \mathrm{C}\right.$, natural photoperiod) and protected from direct sunlight. Each treatment was performed in four replicates of 50 seeds. The dishes were inspected over a 60-day period, on a daily basis for the first two weeks and every two days during the remainder of the period. Filter papers were kept moist with distilled water and germinated seeds were counted and removed during every inspection. Seeds were considered to have germinated when a 1-mm-long radicle emerged. Four different treatments were performed and final germination was expressed as a percentage of germinated seeds per Petri dish.

\section{Experiment I. Low $\mathrm{pH}$ treatment (AT)}

Seeds were sown on a filter paper irrigated with distilled water acidified with $5 \%$ sulphuric acid to reach $\mathrm{pH} 4$. This test simulates the soil $\mathrm{pH}$ conditions of the study area, where E. australis grows. Control seeds were irrigated with distilled water ( $\mathrm{pH} 7)$.

\section{Experiment II. Wet cold stratification}

Two different chilling treatments were performed. The seeds were chilled in wet conditions and kept in darkness at $4{ }^{\circ} \mathrm{C}$ for one month (WCT1) or for 15 days (WCT0.5). The wet-cold stratification recreated the field conditions of seeds remaining in moist soils during rainfall periods in the cold season followed by springtime.

\section{Experiment III. Heat treatments}

Dry seeds were treated with two different temperatures, $80{ }^{\circ} \mathrm{C}$ and $110{ }^{\circ} \mathrm{C}$, both for ten minutes (HT80 and HT110, respectively). Immediately after these pre-treatments, seeds were sown in Petri dishes as described above. Erica australis grows in fire-prone ecosystems, and we therefore chose these temperatures and exposure times considering that several previous studies have verified that, in a fire, heat acts in a specific point during a short lapse of time (between 5 and $15 \mathrm{~min}$ ), and the temperature range is $44-150{ }^{\circ} \mathrm{C}$ to a depth of $2.5 \mathrm{~cm}$ (Trabaud 1979).

\section{Experiment IV. Gibberellic acid (GA) treatments}

Seeds were sown in a solidified medium containing 1\% agar in distilled water and different concentrations of gibberellic acid ( $\mathrm{GA}_{3}$, Sigma). We added GA after melting the agar from concentrated stock $(5000 \mathrm{ppm})$ to reach final concentrations of $0,25,50,100,200$ and $400 \mathrm{ppm}$ GA (GA0, GA25, GA50, GA100, GA200 and GA400, respectively). We chose these treatments considering the enhancing effects of gibberellic acid on germination of many species, e.g., Arabidopsis thaliana (Debeaujon \& Koornneef 2000) and E. andevalensis (Rossini Oliva et al. 2009).

\section{Data analysis}

We analysed the germination data by calculating the average final percentage of germination for each treatment and the cumulative germination curves. Cumulative germination curves were obtained using the Hill regression for three parameters $\left[f(x)=\left(a x^{b}\right) /\left(c^{b}+x^{b}\right)\right]$ with the aid of the Sigma Plot v. 9.0 software. Moreover, to analyse germination dynamics, two parameters: $t_{0}$ and $t_{50}$, were calculated: $t_{0}$ is the time (number of days) between sowing and initial germination and $t_{50}$ is the time (in days) needed to reach $50 \%$ of total germination percentage.

Normality of variables was checked with the Shapiro-Wilks test and homogeneity of the variances by means of the Levene test (Day \& Quinn 1989). Since the data did not fulfil the basic assumptions required to carry out ANOVA, the Mann-Whitney non parametric test was used to detect any significant differences $(p<0.05)$ between pairs of treatments. All the analyses were performed using the SPSS v. 15.0 statistical programme. 


\section{Results}

\section{Effect of low pH}

The germination percentage of acidified seeds was significantly higher than that of the control seeds $(p=0.018)$. Germination of the control seeds was very low $(2 \%-6 \%)$. In the acid-treated seeds, initial germination occurred significantly $(p=0.020)$ earlier than in the control, while the parameter $t_{50}$ did not differ between the two treatments (Table 1).

\section{Effect of wet cold stratification}

The mean germination percentages in control and in cold stratification were statistically different (Table 1). The two cold-stratification treatments enhanced germination in relation to the control $(p<0.05)$ whilst they did not affect the $t_{0}$ and $t_{50}(p>0.05)$. When seeds were subjected to a 15-day period of cold treatment, final germination was approximately nine times higher than that observed in the control seeds. Furthermore, when the cold treatment period was increased (30 days), final germination was significantly higher $(p=0.020)$ than in the seeds treated for 15 days, i.e., 22 times greater than the control values. Furthermore, the seeds chilled for 15 days took less time to start germination (21 days) in comparison with the seeds chilled for 30 days

Table 1. Total germination percentage $(G)$ and germination times $\left(t_{0}\right.$ and $\left.t_{50}\right)$ expressed as mean \pm SD. $t_{0}=$ time between sowing and initial germination; $t_{50}=$ time needed to reach $50 \%$ of final germination percentage. Control (untreated seeds), AT (acid treatment), WCT0.5 and WCT1 (wet cold treatment during 15 days and 1 month respectively), and $\mathrm{HT} 80$ and $\mathrm{HT} 110$ (heat treatments at 80 and $110{ }^{\circ} \mathrm{C}$, respectively). Different letters indicate significant differences $(p<0.05)$ between treatments.

\begin{tabular}{lcrc}
\hline Treatment & $G(\%)$ & $t_{0}$ (days) & $t_{50}$ (days) \\
\hline Control & $3.0 \pm 2.0^{\mathrm{a}}$ & $29 \pm 9^{\mathrm{ac}}$ & $30 \pm 9^{\mathrm{ab}}$ \\
AT & $19.5 \pm 3.4^{\mathrm{b}}$ & $14 \pm 2^{\mathrm{b}}$ & $25 \pm 3^{\mathrm{a}}$ \\
WCT0.5 & $26.0 \pm 5.4^{\mathrm{b}}$ & $21 \pm 2^{\mathrm{a}}$ & $34 \pm 4^{\mathrm{b}}$ \\
WCT1 & $64.5 \pm 12.8^{\mathrm{c}}$ & $33 \pm 2^{\mathrm{c}}$ & $35 \pm 0^{\mathrm{b}}$ \\
HT80 & $89.0 \pm 5.3^{\mathrm{d}}$ & $9 \pm 2^{\mathrm{d}}$ & $21 \pm 2^{\mathrm{a}}$ \\
HT110 & $91.0 \pm 2.6^{\mathrm{d}}$ & $8 \pm 2^{\mathrm{d}}$ & $17 \pm 0^{\mathrm{c}}$ \\
\hline
\end{tabular}

(33 days), whilst parameter $t_{50}$ showed no statistical difference $(p>0.05)$ between both cold stratification treatments.

\section{Effect of heat treatments}

Seeds exposed to either $80^{\circ} \mathrm{C}$ or $110{ }^{\circ} \mathrm{C}$ reached higher germination percentages (close to 90\%) than unexposed seeds (Table 1). The mean germination percentage in both heat treatments was similar $(p>0.050)$, as was the time required to initiate germination. Moreover, in comparison with the control both germination heat treatments reduced $(p=0.018)$ the time required to initiate germination. In addition, in the HT110 seeds the $t_{50}$ was statistically lower with as compared with that in the control and in the HT80 seeds.

\section{Effect of gibberellic acid}

The final germination percentage in all gibberellic acid treatments was significantly higher than in the control $(p<0.050)$ and reached a mean value close to $100 \%$. All germination curves of seeds treated with GA were very similar (Fig. 1). All the GA concentrations tested, even the lowest one $(25 \mathrm{ppm})$, shortened the time necessary to start germination, also shortening $t_{50}$ with respect to the control (Fig. 2) All GA treated seeds presented similar values of $t_{0}$. The time necessary to reach $50 \%$ of final germination decreased statistically from 42 days in the control to 20 days in the $25 \mathrm{ppm}$ GA treated seeds.

\section{Discussion}

All treatments tested in this study significantly increased germination of Erica australis seeds in different proportions. The mean germination percentage of untreated seeds was $3 \%$, a very low value, similar to those obtained in previous studies (Valbuena \& Vera 2002, Díaz Vizcaíno et al. 2006), but lower than values obtained for other Erica species such as E. umbellata, E. vagans (Díaz Vizcaíno et al. 2006) and E. andevalensis (Rossini Oliva et al. 2009). Additionally, E. australis seeds germinated slowly when compared 


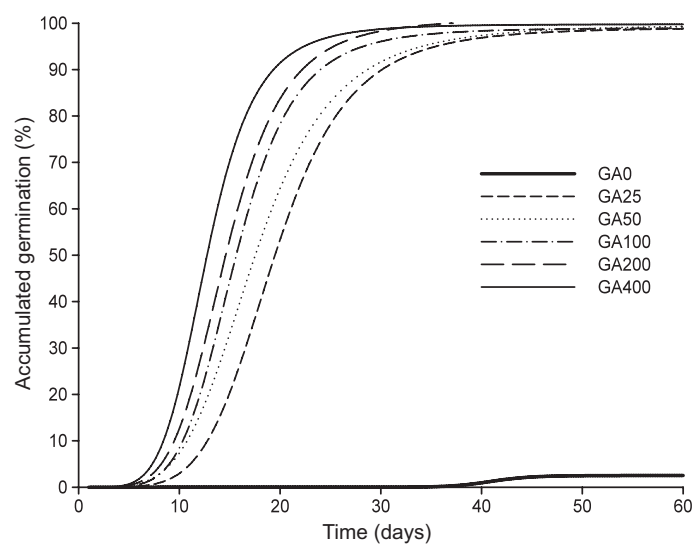

Fig. 1. Germination dynamic of seeds treated with gibberellic acid. GAO, control; GA25, 25 ppm; GA50, 50 ppm; GA100, 100 ppm; GA200, 200 ppm; GA400, $400 \mathrm{ppm}$. Curves fitting by the Hill regression for three parameters.

with the seeds of E. andevalensis (Rossini Oliva et al. 2009).

Cold-stratification, generally in the range of $1-10{ }^{\circ} \mathrm{C}$, is effective for breaking seed dormancy in a number of species (Bewley \& Black 1994) and our results also support this conclusion for E. australis, even if for other Mediterranean species this treatment did not play a crucial role (Giménez-Benavides et al. 2005, Luna et al. 2008). A stratification time of 60 days is useful for removing embryo dormancy in many plants (Bewley \& Black 1994); in E. australis, 15 days of wet cold-stratification were sufficient to break dormancy, although final germination increased approximately three-fold when time of stratification was duplicated.

Erica australis grows in the study area in soils whose $\mathrm{pH}$ ranges from 2.8 to 5.1 , which suggests that its germination might be $\mathrm{pH}$ dependent. When E. australis seeds were irrigated with an acid solution ( $\mathrm{pH} 4)$, germination percentage significantly increased to $24 \%$; moreover, this treatment accelerated germination, as can be observed in the $t_{0}$ value, which was approximately half that for untreated seeds. Results indicate that E. australis germination is stimulated by low $\mathrm{pH}$ values. However, Rossini Oliva et al. (2009) reported that E. andevalensis germination is not $\mathrm{pH}$-dependent.

In Mediterranean fire-prone ecosystems, the enhanced germination and seedling establish-

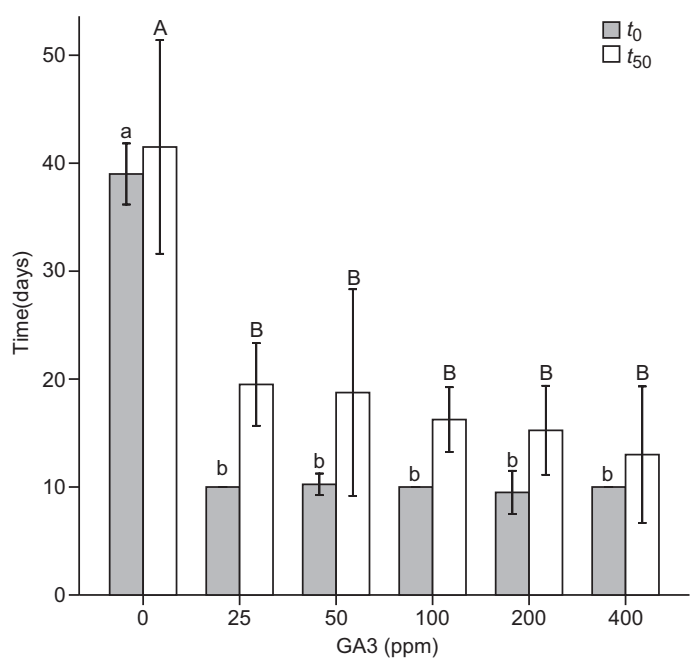

Fig. 2. The effect of gibberellic acid $\left(G_{3}\right)$ on germination time $t_{0}$ and $t_{50}$ expressed as mean \pm SD. Different letters indicate significant means differences $(p<0.05)$.

ment observed in the wet season following wildfires has been referred to as a fire-adaptive response (Keeley \& Bond 1997). Temperatures reached in wildfires affect germination to a greater or lesser degree, according to the position and depth of the seeds in the soil (Trabaud \& Oustric 1989). Fire can stimulate or inhibit germination of the Ericaceae, depending on its duration and intensity (Mesléard \& Lepart 1991). Heat treatments simulating wildfires enhance germination of many Mediterranean species (Obeso \& Vera 1996, Cruz et al. 2003, Díaz Vizcaíno et al. 2006, Luna et al. 2007). Temperature is the most important environmental factor involved in softening of the seed coat (Baskin \& Baskin 1998), as it improves penetration of water into the seed, especially in cases of physical dormancy (Luna et al. 2007). Erica australis showed a clear increase in germination and a decrease in germination time when seeds were treated for 10 minutes at 80 or $110{ }^{\circ} \mathrm{C}$. Results are similar to those reported by Cruz et al. (2003). However, Valbuena and Vera (2002) observed that heating had no effect on the germination of seeds in this species. Díaz Vizcaíno et al. (2006) reported a slight increase when $E$. australis, E. tetralix and E. arborea seeds were pre-heated for 10 minutes at $110^{\circ} \mathrm{C}$, but this pretreatment reduced germination time $\left(t_{0}\right.$ and $\left.t_{50}\right)$ only in E. australis and E. tetralix. 
Non-deep dormancy can be released by means of chemicals such as potassium nitrate, thiourea, kinetin, ethylene and gibberellins (GAs) (Baskin \& Baskin 1998). GAs are known to obviate seeds' requirements regarding various environmental cues, to promote germination, and to counteract the inhibitory effects of abscisic acid (Bewley \& Black 1994). In our study, gibberellic acid applications significantly increased germination, which reached values close to $100 \%$, and positively affected germination dynamics, even when applied at minimum concentrations (25 ppm), which highlights the effective role played by GA in dormancy breaking. Although GA effects on germination were observed in many species (Seiler 1998, Debeaujon \& Koornneef 2000, Delanoy et al. 2006, Ortega-Baes \& Rojas-Aréchiga 2007, Rossini Oliva et al. 2009), this is the first time it has been reported for $E$. australis. Rossini Oliva et al. (2009) observed the same enhancement effect of GA application in $E$. andevalensis seeds, but with lower mean germination values $(41.6 \%$ when 400 ppm GA was applied). In the field, low temperatures increase the level of GA in seeds (Baskin \& Baskin 1998) and under laboratory conditions, GA may substitute the cold stratification requirements for dormancy breaking. In our study, although GA was applied at the minimum concentration, final germination was significantly higher than that obtained in cold stratified seeds. This indicates that gibberellic acid also acts in a different way with regard to breaking dormancy.

Ericaceae seeds are very small, corresponding to the dwarf-seed type according to Martin (1946), and some genera in this family have a very small undifferentiated embryo, which causes morphological-type dormancy (Baskin \& Baskin 1998). Some Ericaceae species have also exhibited physiological dormancy (Aparicio 1995, Rossini Oliva et al. 2009), which contributes to the accumulation of their seeds in the soil, forming persistent seed banks (Baskin \& Baskin 1998). In E. australis, dormancy was broken by cold-stratification, heat shock, low $\mathrm{pH}$ and gibberellins. The present study shows that $E$. australis seeds possess a non-deep physiological dormancy, in accordance with the classification of Nikolaeva (1977), which contrasts with results of Díaz Vizcaíno et al. (2006) and Valbuena and Vera (2002), who observed an intermediate or deep physiological dormancy in this species. Furthermore, other Erica species, such as E. arborea, E. scoparia, E. tetralix (Díaz Vizcaíno et al. 2006) and E. andevalensis (Rossini Oliva et al. 2009), present non-deep dormancy. To our knowledge, seeds with non-deep physiological dormancy are the only ones that can re-enter dormancy, thus exhibiting annual cycles in their dormancy states (Baskin \& Baskin 1998). In the case of E. australis, dormancy break occurs during a wet cold period, which probably means that in the field some seeds $(26 \%-64 \%)$ may germinate after the first rains, which occur mainly in autumn or early winter. Many typical species in Mediterranean-type ecosystems form a persistent soil seed bank which enables them to survive in a risk environment for long periods of the year (Putwain \& Gillham 1990). This is the case of $E$. australis, which forms a seed bank with a large number of seeds that remain in the soil for a certain period of the year. Our results suggest that in the field, almost all E. australis seeds remaining in the bank during a dry season can germinate after rainfall events and cold weather, ensuring the persistence of the species and plant communities at one site for long periods.

\section{Conclusions}

Erica australis seeds present non-deep physiological dormancy, a very low germination percentage and need a long time to start germination (21-42 days). All treatments tested notably improved seed germination. Gibberellic acid treatments provided the best way to increase germination, which reached a value of $100 \%$, even when applied at the lowest concentration tested. The species increased seed germination in response to factors related to the passage of fire and low $\mathrm{pH}$. In accordance with the results, the best method for seed germination in restoration programs involves treating the seeds with 25 ppm of gibberellic acids.

\section{Acknowledgments}

The present research was financed by Fundación Areces 
(Project: "Mecanismos de Resistencia a Metales Pesados en Especies Significativas de la Cuenca Minera de Riotinto").

\section{References}

Aparicio, A. 1995: Seed germination of Erica andevalensis Cabezudo and Rivera (Ericaceae), an endangered edaphic endemic in south-western Spain. - Seed Science and Technology 23: 705-713.

Aparicio, A. 1999: Erica andevalensis Cabezudo \& Rivera. - In: Blanca, G., Cabezudo, B., Hernández-Bermejo, J. E., Herrera, C. M., Molero Mesa, J., Muñoz, J. \& Valdés, B. (eds.), Libro Rojo de la Flora Silvestre Amenazada de Andalucía, tomo I: Especies en peligro de extinción: 119-122. Consejería de Medio Ambiente, Sevilla.

Baskin, C. C. \& Baskin, J. M. 1998: Seeds: ecology, biogeography, and evolution of dormancy and germination. - Academic Press, San Diego.

Baskin, J. M. \& Baskin, C. C. 2004: A classification system for seed dormancy. - Seed Science Research 14: 1-16.

Bewley, J. D. \& Black, M. 1994: Seeds: physiology of development and germination, 2nd ed. - Plenum Press, New York.

Bond, W. \& van Wilgen, B. W. 1996: Fire and plants. Chapman \& Hall, London.

Brown N. A. C. \& van Staden, J. 1997: Smoke as a germination cue: a review. - Plant Growth Regulation 22: 115-124.

Cruz, A., Pérez, B., Velasco, A. \& Moreno, J. M. 2003: Variability in seed germination at the interpopulation, intrapopulation and intraindividual levels of the shrub Erica australis in response to fire-related cues. - Plant Ecology 169: 93-103.

Day, R. W. \& Quinn, G. P. 1989: Comparisons of treatments after an analysis of variance in ecology. - Ecological Monographs 59: 433-463.

Debeaujon, I. \& Koornneef, M. 2000: Gibberellin requirement for Arabidopsis thaliana seed germination is determined both by testa characteristics and embryonic ABA. - Plant Physiology 122: 415-424.

Delanoy, M., Van Damme, P., Scheldeman, X. \& Beltrán, J. 2006: Germination of Passiflora mollissima (Kunth) L. H. Bailey, Passiflora tricuspis Mast. and Passiflora nov sp. seeds. - Scientia Horticulturae 110: 198-203.

Díaz Vizcaíno, E. A., Iglesia Rodríguez, A. \& Fernández, M. 2006: Interannual variability in fire-induced germination responses of the characteristic Ericaceae of the NW Iberian Peninsula. - Forest Ecology Management 234 suppl. 1): S179.

Giménez-Benavides, L., Escudero, A. \& Perez-Garcia, F. 2005: Seed germination of high mountain Mediterranean species: altitudinal, interpopulation and interannual variability. - Ecological Research 20: 433-444

Keeley, J. E. \& Bond, W. J. 1997: Convergent seed germination in South African fynbos and Californian chaparral. - Plant Ecology 133: 153-167.

Kenny, B. 2000: The influence of multiple fire-related germination cues on three Sydney Grevillea (Proteaceae) species. - Austral Ecology 25: 664-669.

Luna, B., Moreno, J. M., Cruz, A. \& Fernández-González, F. 2007: Heat-shock and seed germination of a group of Mediterranean plant species growing in a burned area: An approach based on plant functional types. - Environmental and Experimental Botany 60: 324-333.

Luna, B., Pérez, B., Céspedes, B. \& Moreno, J. M. 2008: Effect of cold-exposure on seed germination of 58 plant species comprising several functional groups from a mid-mountain Mediterranean area. - Ecoscience 15: 478-484.

Martin, A. C. 1946: The comparative internal morphology of seeds. - American Midland Naturalist 36: 513-660.

Merrit, D. J., Kristiansen, M., Flematti, G. R., Turner, S. R., Ghisalberti, E. L., Trengove, R. D. \& Dixon, K. W. 2006: Effects of a butenolide present in smoke on lightmediated germination of Australian Asteraceae. - Seed Science Research 16: 29-35.

Mesléard, F. \& Lepart, J. 1991: Germination and seedling dynamics of Arbutus unedo and Erica arborea on Corsica. - Journal of Vegetation Science 2: 155-164.

Nikolaeva, M. G. 1977: Factors controlling the seed dormancy pattern. - In: Khan, A. A. (ed.), The physiology and biochemistry of seed dormancy and germination: 51-74. North-Holland, Amsterdam/New York.

Obeso, J. R. \& Vera, M. L. 1996: Resprouting after experimental fire application and germination in Erica vagans. - Orsis 11: 155-163.

Ortega-Baes, P. \& Rojas-Aréchiga, M. 2007: Seed germination of Trichocereus terscheckii (Cactaceae): light, temperature and gibberellic acid effects. - Journal of Arid Environments 69: 169-176.

Putwain, P. D. \& Gillham, D. A. 1990: The significance of the dormant viable seed bank in the restoration of heathlands. - Biological Conservation 52: 1-16.

Rivas-Martínez, S. 1979. Brezales y jarales de Europa Occidental. Revisión Fitosociológica de las clases CallunoUlicetea y Cisto-Lavanduletea. - Lazaroa 1: 1-127.

Rossini Oliva, S., Leidi, E. O. \& Valdés, B. 2009: Germination responses of Erica andevalensis to different chemical and physical treatments. - Ecological Research 24: 655-661.

Seiler, G. J. 1998: Seed maturity, storage time and temperature, and media treatment effects on germination of two wild sunflowers. - Agronomy Journal 90: 221-226.

Sutcliffe, M. A. \& Whitehead, C. S. 1995: Role of ethylene and short-chain saturated fatty acids in the smoke-stimulated germination of Cyclopia seed. - Journal Plant Physiology 145: 271-276.

Thompson, K., Ceriani, R. M., Bakker, J. P. \& Bekker, R. M. 2003: Are seed dormancy and persistence in the soil related? - Seed Science Research 13: 97-100.

Trabaud, L. 1979: Etude du comportement du feu dans la Garrige de Chene kermès à partir des temperatures et des vitesses de propagation. - Annales des Sciencies Forestieres 36: 13-38.

Trabaud, L. \& Oustric, J. 1989: Heat requirements for seed germination of three Cistus species in the garrigue of southern France. - Flora 183: 321-325.

Valbuena, L. \& Vera, M. L. 2002: The effects of thermal 
scarification and seed storage on germination of four heathland species. - Plant Ecology 161: 137-144.

Vleeshouwers, L. M., Bouwmeester, H. J. \& Karssen, C. M.
1995: Redefining seed dormancy: an attempt to integrate physiology and ecology. - Journal of Ecology 83: 1031-1037. 